\title{
What Drives Insurers' Demand for Cat Bond Investments? Evidence from a Pan-European Survey
}

\author{
Alexander Braun, Katja Müller and Hato Schmeiser \\ Institute of Insurance Economics, University of St. Gallen, Kirchlistrasse 2, CH-9010 St. Gallen, Schweiz. \\ E-mails: alexander.braun@unisg.ch; katja.mueller@unisg.ch; hato.schmeiser@unisg.ch
}

Although catastrophe bonds are continuing to gain importance in today's risk transfer and capital markets, little is known about the decision-making processes that drive the demand for this aspiring asset class. In the article at hand, we focus on one segment of the investor community. Our research goal is to identify major determinants of the cat bond investment decision of insurance and reinsurance companies. For this purpose, we have conducted a comprehensive survey among senior executives in the European insurance industry. Evaluating the resulting data set by means of exploratory factor analysis and logistic regression methodology, we are able to show that the expertise and experience with regard to cat bonds, the perceived fit of the instrument with the prevailing asset and liability management strategy, as well as the applicable regulatory regime are significant drivers of an insurer's propensity to invest. These statistical findings are supported by further qualitative survey results and additional information from structured interviews with the managers of four large dedicated cat bond funds.

The Geneva Papers (2013) 38, 580-611. doi:10.1057/gpp.2012.51

Keywords: cat bonds; investment decision; insurance companies; exploratory factor analysis; logistic regression; expert interviews

Article submitted 27 June 2012; accepted 7 September 2012; published online 30 January 2013

\section{Introduction}

For almost two decades, insurance and reinsurance companies have been employing insurance-linked securities (ILS) and derivatives to hedge against peak losses in the capital markets. The undoubtedly most successful of these alternative risk transfer measures is the catastrophe (cat) bond, an instrument that allows natural disaster risk to be traded over the counter. As is typical for securitisations, cat bonds are issued out of a special purpose vehicle (SPV), which then holds the principal paid by investors in the form of highly rated collateral. ${ }^{1}$ The sponsoring company enters into a reinsurance contract (or cat swap) with the SPV and, in case a catastrophe occurs and qualifies as

\footnotetext{
${ }^{1}$ Note that until early 2009, cat bonds used to be protected against collateral losses by means of a total return swap (TRS). However, in the aftermath of the financial crisis four transactions ended up in distress, since the default of their swap counterparty Lehman Brothers coincided with a severe impairment of the collateral assets. Consequently, the TRS feature has been removed in more recent transactions. Instead, credit risk is meant to be largely eliminated through stricter collateral arrangements (see, e.g. Towers Watson, 2010).
} 
a trigger event, it is reimbursed with the proceeds of the collateral while investors lose all or part of their principal. To determine whether a payment under the embedded reinsurance contract is due, cat bond structures can feature a variety of different trigger mechanisms. ${ }^{2} \mathrm{Up}$ until a trigger event or maturity, investors are compensated for bearing the natural disaster risk through regular coupons that consist of a floating interest rate such as LIBOR, plus the cat bond spread. ${ }^{3}$ Owing to their comparatively high yields and rather low return correlations with traditional asset classes, cat bonds have repeatedly been described as an appealing investment opportunity. ${ }^{4}$ Yet, the current investor base for this kind of asset is largely dominated by money managers and a few specialised investment funds. This raises questions about the determinants of the institutional demand for cat bonds.

Several authors have discussed potential catalysts and impediments for the evolution of the catastrophe risk markets, considering both traditional reinsurance and securitisation. Froot, ${ }^{5}$ for example, suggests that securitisation can help to improve the efficiency of the distribution of natural hazard losses, and postulates five key success factors for cat bond issues. Furthermore, Niehaus ${ }^{6}$ explores market imperfections that hamper the optimal sharing of disaster risk via reinsurance contracts and cat bonds. In his opinion, the unresolved question of pricing these instruments in a portfolio context has an impact on the demand, since it determines how confident investors are in the zero-beta characteristics of the asset class. Similarly, Froot ${ }^{7}$ develops a number of supply-and-demand-related explanations for the fact that the empirically observed amount of reinsurance and cat bond transactions is considerably lower than suggested by risk management theory. He finds the market power of reinsurance companies and impediments to the inflow of financing from the capital markets to be the most likely reasons for this phenomenon. Another relevant study has been authored by Gibson et al., ${ }^{8}$ who examine why capital-market-based risk transfer solutions have not replaced traditional reinsurance as the primary means for sharing catastrophe risk. They conclude that reinsurance should be preferred in situations where information from the capital markets is costly to acquire and largely redundant. In addition, Cummins and Trainar ${ }^{9}$ consider the advantages and disadvantages of reinsurance and securitisation from a risk management perspective. In this context, they note that cat bonds primarily attract investors due to their still relatively high yields, their low correlation with traditional asset classes, the fact that they are collateralised, and the lower complexity as well as better alignment of interest between investors and ceding companies compared with other types of asset-backed securities (ABS). Apart from that, Ibragimov et al. ${ }^{10}$ derive a model that serves to explain the

\footnotetext{
${ }^{2}$ A description of the different trigger types for cat bonds can, for example, be found in Swiss Re (2006).

${ }^{3}$ See, e.g. Braun (2012).

${ }^{4}$ See, e.g. Litzenberger and Beaglehole (1996), Schoechlin (2002), Cummins and Weiss (2009).

5 Froot (1999).

${ }^{6}$ Niehaus (2002).

${ }^{7}$ Froot (2001).

${ }^{8}$ Gibson et al. (2007).

${ }^{9}$ Cummins and Trainar (2009).

${ }^{10}$ Ibragimov et al. (2009).
} 
limited supply of protection against catastrophe risk offered by insurers and reinsurers. In their view, the typical heavy-tailed loss distributions associated with natural disasters imply a substantial reduction in diversification benefits that may lead to a situation where individual firms do not have an incentive to offer coverage. Finally, Lakdawalla and Zanjani ${ }^{11}$ illustrate that the full collateralisation of cat bonds hinders deeper market penetration, whereas diversification benefits in the context of traditional reinsurance portfolios allow for a more efficient deployment of capital. In their view, this impediment can only be surpassed if securitisations offer substantially lower friction costs than reinsurance contracts.

A related strand of literature is directly concerned with factors that determine the supply of cat bonds by sponsors and the demand for these instruments by investors. Bantwal and Kunreuther ${ }^{12}$ employ behavioural economic aspects such as ambiguity aversion, myopic loss aversion and the fixed costs of education in order to explain institutional asset managers' reluctance to invest in cat bonds. They suggest that, to increase demand and promote further market growth, issuers should aim for a larger degree of security standardisation, reduce pricing uncertainty and strive to enhance investor expertise with regard to the asset class. Moreover, within his comprehensive overview of alternative risk transfer instruments, Cummins ${ }^{13}$ describes cat bonds as a valuable means for portfolio diversification, and emphasises that more standardised and transparent transactions as well as the development of a public secondary market would help to realise the full potential of the asset class. Cummins ${ }^{14}$ additionally mentions the difficulty involved in obtaining transactional information as an obstacle for further growth. A wide range of issues that hinder the expansion of the ILS markets is also discussed in a study by the World Economic Forum. ${ }^{15}$ Among others, the considered problems for sponsors comprise basis risk, the instruments' accounting and regulatory treatment, inconsistent rating methodologies, insufficient data quality and disclosure, the costs of structuring a securitisation deal, and the relatively low level of experience with securitisation in the insurance industry. Investors, on the contrary, are said to be concerned about the lack of standardisation, the limited liquidity and secondary market trading activity, the nontransparent nature of certain trigger mechanisms, and the complexity involved in ILS valuation. Similar problems are identified by Cummins and Weiss ${ }^{16}$ as well as Bouriaux and MacMinn, ${ }^{17}$ who also discuss major demand drivers, such as the risk-return profile and diversification benefits of the asset class and the latest advances in risk modelling methodology. Barrieu and Loubergé, ${ }^{18}$ in contrast, claim that the common arguments for the supposedly disappointing development of the cat bond market to date, such as the lack of investor familiarity with the instrument, parameter uncertainty, and the trade-off

\footnotetext{
${ }^{11}$ Lakdawalla and Zanjani (2011).

12 Bantwal and Kunreuther (2000).

13 Cummins (2005).

${ }^{14}$ Cummins (2008).

15 World Economic Forum (2008).

${ }^{16}$ Cummins and Weiss (2009).

${ }^{17}$ Bouriaux and MacMinn (2009).

${ }^{18}$ Barrieu and Loubergé (2009).
} 
between moral hazard and basis risk, are not convincing. Instead, they suspect downside risk aversion in combination with the ambiguity surrounding the correlation between natural disaster losses and capital market crash scenarios to be responsible for the limited demand. Finally, Hagendorff et al. ${ }^{19}$ draw on the model framework proposed by Merton, ${ }^{20}$ in order to demonstrate that the risk reduction benefits of cat bonds are confined to sponsors with a high default probability or a large exposure to natural disaster risk. They point to this lack of universal applicability as an explanation for the underwhelming development of the market to date.

Despite the relatively large body of literature on supply, demand and growth drivers in the markets for catastrophe risk, to the best of our knowledge, relatively little is known about the motivation of insurance companies to act as cat bond investors. In particular, no analysis of the determinants of their respective investment decision has been conducted to date. Therefore, with this article we aim to address an important research gap by identifying and analysing the main drivers and obstacles with regard to the demand for cat bond investments in the insurance industry. For this purpose, we developed a comprehensive questionnaire that was distributed to senior executives of almost 500 European insurance companies. Moreover, to complement the information received by the survey participants and provide additional evidence for the robustness of our results, we have also conducted structured interviews with the managers of the four largest dedicated cat bond funds that together absorb almost 80 per cent of the outstanding volume. Our findings should provide a thorough insight into the decision-making process that underlies cat bond investments of insurance companies and can thus help to address pressing issues, reduce investment barriers and support further growth of the cat bond market.

The remainder of this article is structured as follows. In the second section, we review the current size and investor base of the cat bond market and develop eight hypotheses concerning the determinants of an insurance company's decision to invest in this asset class. Furthermore, the third section contains a description of our survey as well as a brief introduction to the statistical techniques of exploratory factor analysis and logistic regression that are used to evaluate the resulting data set. The penultimate section represents the main part of the article, including descriptive statistics, the derivation of our key empirical findings, and the discussion of the qualitative results from the open survey questions and expert interviews. Finally, in the last section we draw our conclusions and propose ways to tackle the major barriers that currently seem to prevent insurance companies from engaging in cat bond investments on a larger scale.

\section{The demand for cat bonds}

\section{Current market size and investor base}

Although, in its early days, the cat bond market suffered from low capacities and a lack of investor interest, it has undergone a major development since the 1990s. In the

\footnotetext{
${ }^{19}$ Hagendorff et al. (2011).

${ }^{20}$ Merton (1974).
} 
10 years between 1997 and 2007, issuance volume has increased more than sevenfold from less than US\$1 billion to over US\$7 billion. ${ }^{16}$ Furthermore, Guy Carpenter ${ }^{21}$ estimates that the outstanding risk capital for nonlife cat bonds summed up to more than US $\$ 10$ billion in 2011. Apart from the market size, an evolution could also be observed with regard to the investor base of this asset class. According to Swiss Re, ${ }^{22}$ primary insurers and reinsurers together purchased a total of 55 per cent of the cat bond volume issued in 1999. The remaining demand came from money managers (30 per cent) as well as hedge funds, banks and dedicated cat bond funds (5 per cent each). By 2009, however, the market structure had changed dramatically with dedicated cat bond funds ( 46 per cent), money managers ( 23 per cent) and hedge funds (14 per cent) now providing the vast majority of risk capital. At the same time, the combined share of insurance and reinsurance companies had fallen to a mere 8 per cent. To explain this low level of demand compared with other types of institutional investors, the driving factors behind the investment decision of asset managers in the insurance sector need to be revealed.

\section{Development of hypotheses}

In the following, we develop a total of eight hypotheses that served us as guidance for the design of the questionnaire as well as the schedule for the expert interviews. Although some of the postulated determinants have already been mentioned in earlier articles, they have not yet been empirically tested with an explicit focus on insurance companies as investors.

Large insurers generally have more financial and professional resources at their disposal than small or medium-sized companies. Consequently, they may, for example, afford to put the necessary cat-modelling and data analysis technology in place, hire additional asset management specialists, or establish a dedicated investment team that focuses on ILS. This implies that the sheer size of an insurance company could have an influence on its ability to gain access to the cat bond market and leads us to expect the following:

H1: Larger insurance companies are more likely to invest in cat bonds.

In addition, due to the ever-growing importance of modern risk management techniques and processes, insurers make their investment decisions in accordance with a preset asset and liability management (ALM) strategy. Thus, they will tend to avoid investments that are perceived to be at odds with their ALM goals, while focusing on those that they find to be overall attractive and to fit well into their portfolio. This could, for example, imply that certain firms do not consider investing in risks that they are exposed to through their insurance policies. We therefore state the hypothesis:

H2: The better the perceived fit of cat bonds with the ALM strategy of an insurer, the more likely the company is to invest.

\footnotetext{
${ }^{21}$ Guy Carpenter (2011).

22 Swiss Re (2009).
} 
Asset managers in the insurance industry continuously search for and analyse potential investment opportunities. Owing to the complexity of today's capital markets, specialised in-house expertise and experience is a crucial success factor for the structuring and maintenance of portfolios of a wide range of asset types. In particular, with respect to niche instruments such as cat bonds, a better understanding may lead to a notable increase in investor demand. ${ }^{12}$ Based on this consideration, we postulate:

H3: More expertise and experience with regard to the cat bond asset class increase an insurer's propensity to invest.

It has been repeatedly emphasised that cat bonds exhibit an appealing risk-return profile. ${ }^{16}$ However, insurers need to acknowledge this benefit in order to become interested in the asset class. Hence, we hypothesise:

H4: Insurance companies that perceive the risk-return potential of cat bonds to be advantageous are more likely to invest.

Another characteristic of cat bonds is their typically low correlation with traditional asset classes. ${ }^{17}$ This circumstance provides them with a considerable diversification potential which could influence the investment decision in case insurance companies recognise it. Consequently, we add the following hypothesis:

H5: The propensity of insurers to invest in cat bonds rises with the degree to which they perceive the asset class to offer them diversification benefits.

Furthermore, it can be expected that investors are more likely to purchase cat bonds if they view them to be relatively liquid and standardised assets, which are associated with low administration costs and adhere to transparent pricing rules. ${ }^{15} \mathrm{We}$ summarise these and similar aspects in a factor called perceived administrative complexity and suppose:

H6: The less administrative complexity insurance companies associate with cat bonds, the more likely they are to invest in this asset class.

In general, institutional investors like to decide based on the evaluation of facts and figures. Hence, the decision-making process of insurance companies could be facilitated if, for example, transaction data, pricing information and historical performance figures for the cat bond asset class were readily available. Against this background, it is evident that the currently restricted access to cat bond prospectuses is considered to hamper the development of the market. ${ }^{14}$ Taken together, one could suspect that:

H7: Insurance companies that perceive relevant data and information on cat bonds to be readily available have a higher investment probability.

For the protection of the policyholders' interests, the assets of an insurance company are classified as either tied (restricted) or free. The free assets reflect the firm's equity capital and thus typically account for a comparatively small percentage of the total portfolio. A much larger fraction, in contrast, is represented by the tied assets, which are meant to cover the firm's technical provisions at all 
times. Consequently, they need to adhere to strict requirements with regard to investment types, diversification and risk management.

As will be discussed in the section "Empirical results", all companies in our sample are either subject to EU or Swiss regulation. Explicit lists of asset categories that can be employed to cover the technical provisions of insurers within the European Union are included in Article 21 of the third nonlife insurance Directive of the European Council ${ }^{23}$ and Article 23 of the Directive of the European Parliament and the Council concerning life assurance. ${ }^{24}$ These legal acts comprise a general category termed "debt securities, bonds, and other money and capital market instruments", which, taking into account their fixed income format, also seems applicable to cat bonds. However, in accordance with this EU legislation, individual member states may also establish more detailed guidelines with regard to the characteristics of acceptable investments. In Germany and Austria, for example, the act on the supervision of insurance undertakings (in German: "Versicherungsaufsichtsgesetz", VAG) empowers the government and the national regulatory authority, respectively, to enact provisions that contain binding conditions for the tied assets. ${ }^{25}$ These legal acts, called "Anlageverordnung" 26 in Germany and "Kapitalanlageverordnung" 27 in Austria, do not explicitly rule out cat bond investments and contain an opening clause for those asset classes that are not included in their predefined lists. ${ }^{28}$ Since the requirements with regard to the tied assets in other European countries are also based on the above-mentioned EU directives, they can be assumed to be quite similar. Hence, we do not expect severe regulatory constraints with regard to the cat bond asset class for insurance companies in EU member states.

Furthermore, in Switzerland the act on the supervision of insurance undertakings states that the Swiss Federal Council may enact provisions that govern tied assets and leave it up to the Swiss Financial Market Supervisory Authority (FINMA) to determine additional details. ${ }^{29}$ The respective guidelines have been incorporated into Article 79(1) of the "Aufsichtsverordnung" 30 and are further substantiated in FINMA's circular letter on the investment of tied assets. ${ }^{31}$ Clause II.D.a of this document, which includes the general principles with regard to eligible investments, states that the tied assets must not include insurance risk, and clause III.C.b.bb explicitly forbids the purchase of ILS. Hence, Swiss insurers may only consider cat bond investments within their free assets. This implies that their asset management departments have less options to employ the instrument than those of their

\footnotetext{
23 Directive 92/49/EEC (1992).

${ }^{24}$ Directive 2002/83/EC (2002).

${ }^{25}$ See paragraph 54(2) VAG Germany and paragraph 78(3) VAG Austria.

${ }^{26}$ AnlV (2011).

${ }^{27}$ KAVO (2012).

${ }^{28}$ These opening clauses can be found in paragraph 2(2) AnlV and paragraph 2(1) No. 9 KAVO.

${ }^{29}$ See Article 20 VAG Switzerland.

30 AVO (2009).

31 See FINMA (2008).
} 
European counterparts. The consideration of this legal background results in our last hypothesis:

H8: Owing to binding regulatory constraints, Swiss insurers are less likely to invest in cat bonds.

In this context it should be noted that regulatory constraints in the broader sense could also arise due to the capital requirements associated with cat bond investments under the Swiss Solvency Test (SST) or Solvency II. More specifically, if an insurer perceives the resulting capital charges to be ambiguous or inappropriate, it could tend to avoid the asset class. However, under both regulatory frameworks cat bond investments are virtually treated in the same way as the catastrophe risk exposure incurred through traditional (re)insurance contracts. Hence, we do not expect a significant impact on the investment decision of insurance companies and refrain from formulating an explicit hypothesis. Similarly, we deem it unlikely that the accounting treatment of the instrument turns out to be relevant in this regard. Nevertheless, our survey included a set of questions to measure the firm's perception of the capital requirements and accounting treatment of cat bond investments. Based on the corresponding information, the correctness of these expectations will be confirmed.

\section{Data and methodology}

\section{Questionnaire design}

Before the development of our questionnaire, we engaged in an intensive dialogue with ILS experts from a large Swiss reinsurance company. The aim was to identify and better understand the potential drivers of the demand for cat bond investments. Apart from the company size and constraints due to the regulatory regime, the determinants hypothesised in the previous section are latent variables, that is, multifaceted constructs that cannot be directly observed. Thus, in order to capture each relevant factor as comprehensively as possible, we devised specific measurement variables (also called observed variables or items). ${ }^{32}$ After the preparation of a first questionnaire draft, we again consulted industry professionals and academics to obtain feedback concerning wording and completeness, based on which we implemented final changes by rephrasing, adding or deleting certain items. A high-level overview of the chosen questionnaire structure can be found in Figure 1. In part A, we inquired key facts related to the answering insurance company, such as the country of incorporation, the business model (insurer, reinsurer), the number of employees, the balance sheet size and the premium volume. Furthermore, part B constituted of questions with regard to the firm's cat bond investment activities. Parts $\mathrm{C}$ to $\mathrm{H}$ contained sets of measurement variables for the determinants' experience and expertise, perceived riskreturn and correlation characteristics, perceived administrative complexity, perceived

\footnotetext{
${ }^{32}$ To the best of our knowledge, there are no existing item sets in the literature that would fit the context of our study.
} 


\begin{tabular}{|c|}
\hline A. Company Background \\
\hline B. Cat Bond Investments \\
\hline C. Experience and Expertise with the Cat Bond Asset Class \\
\hline D. Risk-Return and Correlation Characteristics \\
\hline E. Administrative Complexity \\
\hline F. Availability of Data and Information \\
\hline G. Accounting Treatment \\
\hline H. Capital Requirements \\
\hline \\
\hline I. Further Comments \\
\hline
\end{tabular}

Figure 1. Overview of the questionnaire structure.

availability of data and information, as well as accounting treatment and capital requirements. In the final part, the participants were given the opportunity to provide further comments. Altogether, the questionnaire comprised 41 items which were measured on six-point Likert scales. ${ }^{33}$ Potential biases due to respondents who are too unfamiliar with the subject to provide a reliable opinion are minimised, since we also allowed to select a "do not know" button for each item.

\section{Participant recruitment}

To recruit relevant participants for our web-based survey, we made use of the key informant technique. The aim was to contact senior executives, preferably CEOs and CFOs, since they should be well informed about the companies' strategic investment decisions as well as the corresponding reasons behind them. Hence, we collected the addresses of a total of 490 insurance and reinsurance companies from Austria, France, Germany, Italy, the Netherlands, Sweden, Switzerland, the U.K., Finland, Portugal, Belgium and Greece. Based on the gathered information, we invited the targeted participants by email to take part in our survey. The questionnaire was made available online in early February 2012. Two reminders were sent out via email, one after three and another one after six weeks. In total, the companies had nine weeks' time to complete the questionnaire. While survey participation in general was anonymous,

${ }^{33}$ Likert scales are a common way to capture an individual's level of agreement or disagreement with a specific statement (see Likert, 1932). An even number of points means that a neutral answer is not possible. Instead, the respondent is forced to choose a positive or negative stance. 
respondents were offered to receive the results of our study if they chose to provide their contact information.

\section{Sample characteristics and imputation}

Overall, 64 companies reacted to the invitation, which corresponds to a response rate of 13.1 per cent. On average, it took the participants 11 minutes to complete the survey. However, a number of firms terminated the questionnaire prematurely. We therefore imputed missing values as far as possible and removed all cases for which key items were missing and imputation was impossible. Our final data set is based on the responses of 44 participants, who completed the essential parts of the questionnaire, such as the company background and the question as to whether or not they have invested in cat bonds in the past and/or plan to do so in the future. ${ }^{34}$ Of these 44 participants, 36 provided their views on all the included item sets. This subsample is used for the inference statistical analysis.

\section{Exploratory factor analysis}

The factor scores for each potential determinant are derived by means of exploratory factor analysis (EFA), a statistical methodology that explains the covariance (correlation) structure of observed random variables in terms of a smaller number of latent variables. The following is an analytical representation of the general EFA model ${ }^{35}$ :

$$
\mathbf{X}=\Lambda \xi+\delta
$$

where $\mathbf{X}$ is the vector of observed variables, $\Lambda$ represents the factor loadings matrix, $\xi$ is the vector of latent variables (factors), and $\delta$ stands for the vector of unique factors (residuals). Applying matrix algebra, one can derive the covariance matrix $\Sigma$ implied by the model:

$$
\Sigma=\Lambda \Phi \Lambda^{\prime}+\Psi_{\delta}
$$

with $\Phi$ being the covariance matrix of the factors and $\Psi_{\delta}$ denoting the covariance matrix of the residuals. ${ }^{36}$ The parameters (factor loadings and residual variances) for the EFA model are determined by means of maximum likelihood estimation (MLE), so that the model-implied covariance (correlation) matrix fits its empirically observed counterpart as closely as possible. ${ }^{37}$ Based on the derived factor loadings, one can compute factor score estimates $\xi$ that may be used to represent the determinants of the cat bond investment decision in further analyses. For this purpose, we select the so-called

\footnotetext{
${ }^{34}$ Fourteen of the participants provided us with information about their positions in the company. According to their statements, five Chief Investments Officers and two other members of the executive boards answered our questionnaire. Furthermore, two survey participants are directors, whereas another five claimed they are Head of Asset Management or Senior Risk Manager. Thus, we believe that we did manage to approach the key informants we wanted to.

35 The notations in this subsection have been adopted from Jöreskog (1967).

${ }^{36}$ When EFA is conducted with standardised variables, $\Phi$ reduces to the identity matrix.

${ }^{37}$ Note that classical EFA requires the observed variables to be normally distributed.
} 
regression method, which employs the sample covariance matrix $\hat{\Sigma}$ and the estimated factor loadings matrix $\Lambda$ as follows:

$$
\hat{\xi}=\hat{\Lambda}^{\prime} \hat{\Sigma}^{-1} X
$$

\section{Logistic regression model}

To address our main research question, we require a statistical methodology that determines the influence of a set of $k$ metric explanatory (predictor) variables $x$ on a binary (dichotomous) dependent variable $y$, that is, one that takes on only two values: one and zero (investor and non-investor). In the following, the sampling units (insurance companies) will be indexed by $i(i=1, \ldots, N)$. To begin with, consider the following linear regression model:

$$
y_{i}=\beta_{0}+\beta_{1} x_{i 1}+\beta_{2} x_{i 2}+\cdots+\beta_{k} x_{i k}+\varepsilon_{i}=\mathbf{x}_{i}^{\prime} \boldsymbol{\beta}+\varepsilon_{i},
$$

where $y_{i}$ represents the value of the dependent variable for insurance company $i, x_{i k}$ is the value of the independent variable $k$ for insurance company $i$, the $\beta_{k}$ are the regression coefficients (including an intercept $\beta_{0}$ ), and $\varepsilon_{i}$ denotes the zero-mean disturbance term. In matrix notation, the information about the predictor variables is contained in the column vector $\mathbf{x}_{i}$ and $\boldsymbol{\beta}$ represents the vector of regression coefficients. Instead of the dichotomous variable itself, binary response models predict the probability $\pi_{i}$ that $y_{i}$ assumes a value of one, given $\mathbf{x}_{i}$. Since $y_{i}$ is dichotomous, we know that $\pi_{i}=\operatorname{Pr}\left[y_{i}=1\right]=\mathrm{E}\left(y_{i}\right)$. In conjunction with Eq. (4), we get:

$$
\pi_{i}=\mathbf{x}_{i}^{\prime} \boldsymbol{\beta}
$$

Eq. (5) is known as the linear probability model (LPM) and can be estimated by means of ordinary least squares (OLS) methodology. Unfortunately, this simple choice approach suffers from a number of drawbacks: it may produce outcomes of less than zero and greater than one (out-of-bounds predictions), it violates the basic OLS assumption of homoskedastic residuals, and the corresponding error distribution is non-normal. ${ }^{38}$ These issues can be avoided by drawing on the well-established logit model, which links the predictors to the probabilities by means of the sigmoid shaped logistic function $P(z)=1 /(1+\exp (-z))^{39}$ :

$$
\pi_{i}=P\left(\mathbf{x}_{i}^{\prime} \boldsymbol{\beta}\right)=\frac{1}{1+\exp \left(-\mathbf{x}_{i}^{\prime} \boldsymbol{\beta}\right)} .
$$

The linear combination $\mathbf{x}_{i}^{\prime} \boldsymbol{\beta}$ describes a latent variable $z$, called the logit. Accordingly, in logistic regression terminology, the elements of $\boldsymbol{\beta}$ are known as logit coefficients. They are determined by means of MLE, that is, the (log-)likelihood

\footnotetext{
${ }^{38}$ See, e.g. Wooldridge (2008).

${ }^{39}$ The logistic function $\mathrm{P}($.$) is also the cumulative distribution function (cdf) of a standard logistically$ distributed random variable. It translates any real number into a value between zero and one.
} 
function is maximised by means of a numerical algorithm in order to identify the logit coefficients that are most likely associated with the observed values for $y$ and $\mathbf{x}$. The logit is the natural logarithm of a magnitude $\Omega$, termed the odds, which equals the probability of the dependent variable taking on the value one divided by the probability of it taking on the value zero, conditional on the set of predictors:

$$
\Omega=\frac{\operatorname{Pr}(y=1 \mid x)}{\operatorname{Pr}(y=0 \mid x)}=\frac{1 /\left(1+\exp \left(-\mathbf{x}_{i}^{\prime} \boldsymbol{\beta}\right)\right)}{1-1 /\left(1+\exp \left(-\mathbf{x}_{i}^{\prime} \boldsymbol{\beta}\right)\right)}=\exp \left(\mathbf{x}_{i}^{\prime} \boldsymbol{\beta}\right)
$$

Being confined to the interval $[0,+\infty)$, the odds are another measure of effect strength in the logistic regression model. If they equal one, both outcomes of the dependent variable are equally likely. The further they deviate from one, the stronger the (positive or negative) link between the dependent variable and the regressors. ${ }^{40}$

\section{Empirical results}

\section{Descriptive statistics}

In this section, we present descriptive statistics to characterise the composition of our sample. The first column of Table 1 shows the numbers and percentages of insurance companies categorised by country, business model (insurer, reinsurer), business line (life, nonlife, multiline) and geographic investment scope (global, regional). In addition, we indicate whether or not the firms act as cat bond sponsors, invest in securitisations in general and belong to a larger insurance group. Accounting for 31.82 per cent of the survey respondents, Swiss insurers are slightly overweighted in the data set. Apart from that, however, the participants are relatively evenly spread across European countries. Furthermore, almost 80 per cent of the covered firms are primary insurers. This is a positive indication for the representativeness of the sample, since reinsurers are also much rarer in the reference population, i.e. European insurance companies. Similarly, a majority of about 70 per cent run a multiline insurance business, comprising both life and nonlife divisions. ${ }^{41}$ With respect to their geographic investment scope, around 60 per cent replied that they exclusively focus on regional (national or European) assets and markets, while only 40 per cent consider themselves to be global investors. Hence, we seem to have a well-balanced mix of small, medium-sized and large companies. Moreover, more than 80 per cent of the respondents stated that they do not act as cat bond sponsors. Again, this implies that the data should be representative, since only a few large primary insurers and reinsurers in Europe with the resources and capabilities to sponsor and structure cat bond

\footnotetext{
${ }^{40}$ Note that $\pi, z$ and $\Omega$ essentially provide the same information. A probability $\pi_{i}$ of 0.5 corresponds to a $\operatorname{logit} z$ of 0 and odds $\Omega$ of 1 . Each of these values implies that both outcomes of $y$ exhibit the same likelihood.

${ }^{41}$ Four of the firms in this category responded that they additionally run a health insurance line.
} 
Table 1 Sample composition

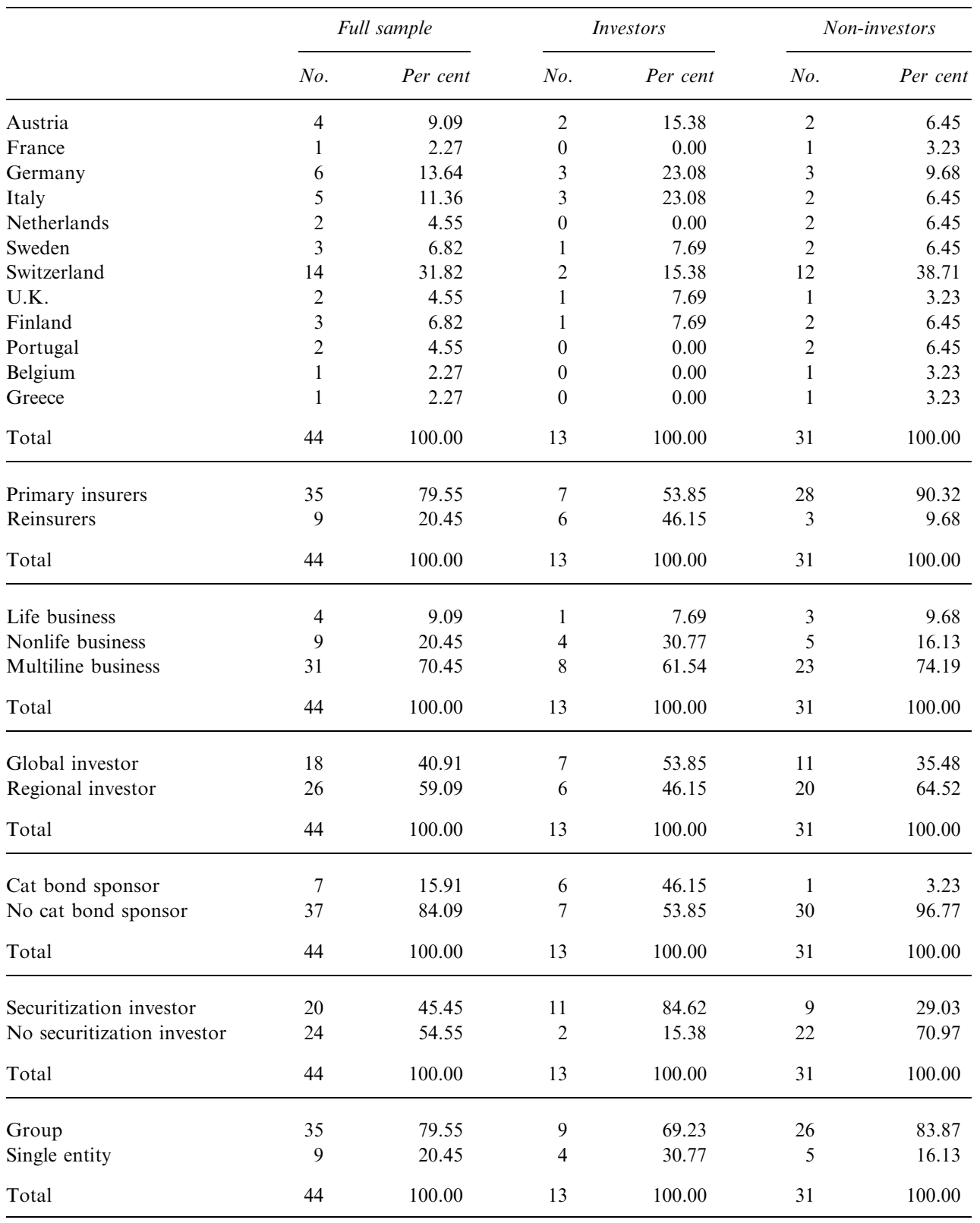

This table shows the composition of the sample of 44 firms that has been generated from the respondents of a survey among 490 European insurers and reinsurers. The data are categorised by country, business model (insurer, reinsurer), business line (life, nonlife, multiline), geographic investment scope (global, regional), sponsoring activity (cat sponsor, no sponsor), other securitisation investments such as ABS, CDOs and covered bonds (investor, noninvestor), as well as organisational structure (single entity, insurance group). In addition, each category is further differentiated into cat bond investors and non-investors. Cat bond investors are defined as those insurance companies, which stated that they will continue or begin to hold cat bonds in their asset portfolios in the future. 
transactions have actually employed this risk transfer instrument to date. Finally, half of the firms in the sample invest in at least one other type of securitisation, such as ABS, collateralised debt obligations (CDOs) or covered bonds, and the vast majority of the responding entities are part of a group.

In the second and third column of Table 1, we have split the sample into those firms that do and those that do not invest in cat bonds. ${ }^{42}$ As could be expected, only 29.55 per cent $(=13 / 44)$ of the respondent firms actually invest in cat bonds. Taking into account the low percentage of insurers among the current investor base of the cat bond asset class as discussed in the section "Current market size and investor base", the large fraction of 70.45 per cent $(=31 / 44)$ non-investors is another cue for the representativeness of our sample. Interestingly, the majority of investors (61.54 per cent) come from Austria, Germany or Italy, whereas most non-investors in the sample are based in Switzerland (38.71 per cent). Furthermore, over 90 per cent of the non-investors are primary insurers. In contrast to that, more than 45 per cent of the investors are reinsurers or, to put it differently, two-thirds $(=6 / 9)$ of the reinsurers in the sample do invest in cat bonds. This might be some initial evidence for Hypotheses 1, 2 and 3, since the firm's size, the fit of cat bonds with its ALM strategy as well as the expertise and experience with the asset class are characteristics that can be expected to vary considerably between the average primary insurer and reinsurer. Similarly, the fact that almost all noninvestors (96.77 per cent) also do not act as cat bond sponsors and a majority of them have a regional investment focus (64.52 per cent) supports these hypotheses, because the cat bond sponsoring business is dominated by large and experienced reinsurance companies. Insurers with a geographically limited asset management scope, on the other hand, are likely to be smaller and less familiar with rather exotic asset classes such as cat bonds. In addition, judging by the higher share of pure nonlife insurers among the investors, it seems that the propensity to purchase cat bonds might somehow be related to the risk expertise that an insurance company accumulates through its business lines. Lastly, we observe that almost 85 per cent of the cat bond investors in our sample also hold other securitisations, while more than 70 per cent of the non-investors do not. Thus, the experience with and the general affinity to invest in securitised assets could also exert an influence on insurance companies' demand for cat bonds.

Table 2 contains mean, median, standard deviation, minimum and maximum for the number of employees, the balance sheet size and the premium volume of the firms in our sample. These variables have been included in the survey as proxies for the company size. Again, we additionally distinguish between investors and non-investors. When examining the respective figures, we notice that for all three variables the medians are smaller than the means, that is, the distributions seem to exhibit some degree of positive skewness (long right tail). Moreover, the minimum and maximum values indicate that the sample covers a range of very differently sized companies. The smallest insurer, for example, employs only 14 staff members, while the largest workforce amounts to 60,000 people. ${ }^{43}$ Similar observations can be made for the

\footnotetext{
${ }^{42}$ We define cat bond investors as those insurance companies which stated that they will continue or begin to hold cat bonds in their asset portfolios in the future.

${ }^{43}$ Note that all entities with less than 4,000 employees are part of insurance groups.
} 
Table 2 Descriptive statistics for the company sizes

\begin{tabular}{|c|c|c|c|c|c|c|c|}
\hline & Mean & Median & $S D$ & Minimum & Maximum & $K-S$ stat. & $p$-value \\
\hline \multicolumn{8}{|l|}{ Full sample } \\
\hline No. of employees & $6,667.80$ & $1,225.00$ & $13,365.14$ & 14.00 & $60,000.00$ & 0.3224 & $0.0002 * * *$ \\
\hline Balance sheet (mn EUR) & $38,975.24$ & $10,492.93$ & $78,202.53$ & 0.18 & $400,000.00$ & 0.3249 & $0.0002 * * *$ \\
\hline Premium volume (mn EUR) & $8,529.05$ & $1,775.00$ & $18,971.43$ & 0.11 & $107,900.00$ & 0.3265 & $0.0002 * * *$ \\
\hline \multicolumn{8}{|l|}{ Investors } \\
\hline No. of employees & $9,102.85$ & $1,250.00$ & $17,035.41$ & 87.00 & $47,000.00$ & 0.3644 & $0.0633^{*}$ \\
\hline Balance sheet (mn EUR) & $50,347.32$ & $22,500.00$ & $84,651.67$ & 360.00 & $240,000.00$ & 0.3732 & $0.0392 * *$ \\
\hline Premium volume (mn EUR) & $8,580.91$ & $3,735.00$ & $11,197.83$ & 460.00 & $32,600.00$ & 0.2774 & 0.2697 \\
\hline \multicolumn{8}{|l|}{ Non-investors } \\
\hline No. of employees & $5,646.65$ & $1,200.00$ & $11,674.88$ & 14.00 & $60,000.00$ & 0.3147 & $0.0043 * * *$ \\
\hline Balance sheet (mn EUR) & $34,206.30$ & $9,296.00$ & $76,287.88$ & 0.18 & $400,000.00$ & 0.3334 & $0.0020 * * *$ \\
\hline Premium volume (mn EUR) & $8,507.31$ & $1,308.00$ & $21,580.55$ & 0.11 & $107,900.00$ & 0.3766 & $0.0002 * * *$ \\
\hline
\end{tabular}

This table contains the mean, median, standard deviation, minimum and maximum for the number of employees, the balance sheet size and the premium volume of the insurance companies in the sample. These three variables serve as proxies for the firm size. In addition, location and dispersion statistics have been provided separately for the subsamples of cat bond investors and non-investors. The last three columns show the results of a Kolmogorov-Smirnov (K-S) test of the null hypothesis that the variables are normally distributed.

Significance levels: $* * *=1$ per cent, $* *=5$ per cent, $*=10$ per cent.

Table 3 Mann-Whitney U-test

\begin{tabular}{lrlllr}
\hline No. of employees & & Balance sheet size (mn EUR) & Premium volume (mn EUR) \\
\hline$N$ & 44 & $N$ & 44 & $N$ & 44 \\
Mann-Whitney $U$ & 218.0000 & Mann-Whitney $U$ & 237.5000 & Mann-Whitney $U$ & 249.0000 \\
Standard error & 39.6440 & Standard error & 39.6820 & Standard error & 39.6850 \\
$p$-value & 0.8400 & p-value & 0.4880 & $p$-value & 0.3260 \\
\hline
\end{tabular}

Results of a Mann-Whitney U-test to assess whether the differences in the average number of employees, balance sheet size and premium volume between investors and non-investors are statistically significant. The test is based on the null hypothesis that the two samples under consideration have been drawn from the same distribution.

balance sheet sizes and premium volumes. A simple comparison of the sample means of these three size proxies between investors and non-investors reveals that, on average, the former are larger. However, since this discrepancy could be simply caused by the random draw through our survey, one needs to rely on statistical inference in order to make a statement about the underlying population of European insurance companies. The most common procedure in this regard is the two-sample $t$-test for the equality of means. The typical prerequisites for this test are normally distributed data, equal sample sizes and equal sample variances. ${ }^{44}$ The former condition can be checked by means of the Kolmogorov-Smirnov (K-S) goodness-of-fit test, the results of which are displayed in the last two columns of Table 2 . Since we reject the null hypothesis of

${ }^{44}$ See, e.g. Sawilowsky and Blair (1992). 
Table 4 Potential determinants of the investment decision

\begin{tabular}{|c|c|c|c|c|c|c|c|c|c|}
\hline \multirow[t]{2}{*}{ Determinant } & \multicolumn{3}{|c|}{ Full sample } & \multicolumn{3}{|c|}{ Investors } & \multicolumn{3}{|c|}{ Non-investors } \\
\hline & Relevant & Irrelevant & Sum & Relevant & Irrelevant & Sum & Relevant & Irrelevant & Sum \\
\hline Expertise/experience & 15 & 21 & 36 & 8 & 4 & 12 & 7 & 17 & 24 \\
\hline in per cent & 41.67 & 58.33 & 100.00 & 66.67 & 33.33 & 100.00 & 29.17 & 70.83 & 100.00 \\
\hline Risk/return/correlation & 16 & 20 & 36 & 10 & 2 & 12 & 6 & 18 & 24 \\
\hline in per cent & 44.44 & 55.56 & 100.00 & 83.33 & 16.67 & 100.00 & 25.00 & 75.00 & 100.00 \\
\hline Administrative complexity & 16 & 20 & 36 & 9 & 3 & 12 & 7 & 17 & 24 \\
\hline in per cent & 44.44 & 55.56 & 100.00 & 75.00 & 25.00 & 100.00 & 29.17 & 70.83 & 100.00 \\
\hline Data availability & 12 & 24 & 36 & 8 & 4 & 12 & 4 & 20 & 24 \\
\hline in per cent & 33.33 & 66.67 & 100.00 & 66.67 & 33.33 & 100.00 & 16.67 & 83.33 & 100.00 \\
\hline Accounting treatment & 7 & 29 & 36 & 4 & 8 & 12 & 3 & 21 & 24 \\
\hline in per cent & 19.44 & 80.56 & 100.00 & 33.33 & 66.67 & 100.00 & 12.50 & 87.50 & 100.00 \\
\hline Capital requirements & 10 & 26 & 36 & 3 & 9 & 12 & 7 & 17 & 24 \\
\hline in per cent & 27.78 & 72.22 & 100.00 & 25.00 & 75.00 & 100.00 & 29.17 & 70.83 & 100.00 \\
\hline
\end{tabular}

Numbers and percentages of the insurance companies that stated whether or not a certain factor has influenced their decision to invest in cat bonds. Owing to the exclusion of cases with missing data, the overall sample size drops to $N=36$.

normality in all cases but one (see $p$-values), the aforementioned two-sample $t$-test will not be applied. Instead, we decide to conduct the more robust Mann-Whitney U-test to assess whether the differences in the means between investors and non-investors are statistically significant. This nonparametric test is based on the null hypothesis that the two samples under consideration have been drawn from the same distribution. The results are shown in Table 3. For all three size proxies (number of employees, balance sheet size, premium volume) the $p$-values exceed 0.1 . To put it differently, this is a first indication that company size might not matter with regard to the cat bond investment decision of insurance companies.

Finally, to get an initial impression of the importance of some of the potential determinants discussed in the section "Development of hypotheses", we have asked the insurance companies that participated in the survey to state whether or not certain factors had an influence on their cat bond investment decision. ${ }^{45}$ Table 4 shows the respective results. ${ }^{46}$ Interestingly, the aspects expertise and experience, risk-return (and

\footnotetext{
${ }^{45}$ As explained in the section "Exploratory factor analysis", most of the determinants are latent factors, which have been measured by means of observed variables or so-called items. Within the questionnaire, each determinant was represented by a whole battery of such items. The relevant/irrelevant questions to which we refer in this paragraph preceded those item batteries. The only exception is the factor "perceived fit with the company's ALM strategy" (Hypothesis 2), for which a relevance/irrelevance question has not been posed. The reason is that the respective item battery was included in a more general section of the questionnaire that captured further details with regard to the firm's past, present and future cat bond investments.
} 
correlation) profile, administrative complexity, and data availability are considered relevant by the majority of investors, while they do not seem to be of importance to most non-investors. Constraints due to capital charges and accounting issues, in contrast, have been declared to be irrelevant by both groups. This finding supports our expectation that these two aspects do not affect an insurance company's propensity to invest in cat bonds.

\section{Exploratory Factor Analysis Results}

Before estimating the logistic regression model, we run an EFA to extract a set of latent constructs from the observed variables in our sample. For the resulting factor structure to be meaningful and properly interpretable, the correlations between items that are associated with the same factor should be high, while those between items that represent different factors should be low. This idea underlies the Kaiser-Meyer-Olkin (KMO) measure of sampling adequacy, which indicates whether a data set is suitable for an EFA. Being defined between zero and one, KMO values below 0.5 imply that EFA should not be applied, whereas KMO values in excess of 0.8 mean that the sample is particularly well suited for the analysis. ${ }^{47}$ Following an iterative process guided by the KMO measure, we identified 15 of the 41 items as problematic and removed them from our sample. The remaining 26 items lead to a solid KMO value of 0.7041 . Furthermore, in order to check the EFA precondition of normality, the K-S goodness-of-fit test has been employed. Apart from very few exceptions, we do not find significant deviations from the normal distribution, implying that the items can be used in a factor analysis. ${ }^{48}$ Subsequently, we conduct Bartlett's test of sphericity and find the correlations of the items to be statistically significant on the 1 per cent level with a $\chi^{2}$ test statistic of $1,106.16$ and 325 degrees of freedom. Since the EFA procedure relies on the correlation (covariance) matrix of the observed variables to derive the latent constructs, this test result is another indication for the suitability of our data.

For the initial factor extraction we choose the principal components analysis. This procedure produces an orthogonal factor structure (i.e. the pairwise factor correlations are zero) by repeatedly searching for linear combinations of the items that account for the largest fraction of the still unexplained variance, until the number of extracted factors equals the number of items. ${ }^{49}$ The usual result is that, on the one hand, the majority of items strongly load on the first few factors and, on the other hand, substantial cross-loadings of items with more than one factor arise. Consequently, it is common to rotate the extracted factor structure in order to generate a more coherent pattern of loadings that considerably improves interpretability. ${ }^{50}$ For this purpose, we resort to the orthogonal varimax rotation approach,

\footnotetext{
${ }^{46}$ Note that the number of respondents $N$ has dropped from 44 to 36 , since eight firms have not provided information with regard to the item batteries for the latent variables at all. Hence, imputation was not possible and the respective cases have been excluded from the following analyses due to missing data.

47 See Kaiser (1974).

${ }^{48}$ Owing to the standard nature of the K-S statistic and the multitude of variables, we decided not to report these results.

49 Taken together, the principal components explain the total variance of all items.
} 
Alexander Braun et al

Table 5 Rotated factor loadings matrix with additional statistics

\begin{tabular}{|c|c|c|c|c|c|}
\hline Item & Factor 1 & Factor 2 & Factor 3 & Factor 4 & Factor 5 \\
\hline \multicolumn{6}{|l|}{ Cat bonds ... } \\
\hline ... fit well in our portfolio & & & & & 0.8440 \\
\hline$\ldots$ are compatible with our ALM strategy & & & & & 0.9165 \\
\hline$\ldots$ are an attractive asset class & 0.4792 & & 0.4125 & & 0.6470 \\
\hline \multicolumn{6}{|l|}{ Our firm .... } \\
\hline$\ldots$ is very experienced in the asset class & 0.8706 & & & & \\
\hline$\ldots$ has a strong cat bond expertise & 0.8930 & & & & \\
\hline ... fully understands the typical risks & 0.8171 & & & & \\
\hline ... can handle the modelling/valuation/risk mgmt & 0.9292 & & & & \\
\hline ... possesses cat bond portfolio mgmt skills & 0.8915 & & & & \\
\hline$\ldots$ understands the accounting treatment & 0.8479 & & & & \\
\hline ... understands the regulatory treatment & 0.7481 & & & & \\
\hline ... commands the necessary overall resources & 0.9126 & & & & \\
\hline
\end{tabular}

The following information is readily available:

Transaction data

0.9066

0.8346

0.5494

0.7486

0.8976

0.9489

0.5020

0.8025

0.7539

0.8458

0.4828

0.7713

0.6568

0.5616

0.8083

0.4289

0.6631

0.8532

0.7821

$\begin{array}{rrrrr}8.9929 & 6.7188 & 2.1114 & 1.9237 & 1.7278 \\ 34.5879 & 25.8416 & 8.1209 & 7.3990 & 6.6455 \\ 34.5879 & 60.4295 & 68.5504 & 75.9494 & 82.5949 \\ 0.9653 & 0.9318 & 0.9152 & 0.8761 & 0.8819\end{array}$

Eigenvalues

Explained variance (per cent)

Cumulative explained variance

Cronbach's $\alpha$
0.8440

0.9165

.6470

Factor loadings resulting from an EFA for 26 items that have been measured on Likert scales. KMO measure of sampling adequacy: 0.7041. Bartlett's test of sphericity: $\chi^{2}$-value $=1,106.16,325$ degrees of freedom, $p$-value $=0.0000$. Extraction method: principal component analysis. Rotation method: varimax with Kaiser normalisation. Dimensionality: all factors that are compatible with a hypothesis and exhibit eigenvalues greater than unity have been retained (Kaiser criterion). This leads to a five-factor solution. In order to enhance the readability and interpretability of this table, factor loadings below 0.4000 have been suppressed. The eigenvalue of each factor (i.e. the sum of squared factor loadings across all items) is a measure for the amount of variance it explains. In sum, the five factors explain 82.5949 per cent of the total variance. Cronbach's alpha has been computed to measure the internal consistency of each item battery.

${ }^{50}$ In rotated factor structures, each item tends to load relatively high on one of the factors, while exhibiting rather weak cross-loadings with the others. 
which repositions the axes of the factor space such as to maximise the variance of the squared loadings per factor. Moreover, since EFA does not provide a theoretical foundation for the number of factors to be retained, our hypotheses serve as the main guidance for the dimensionality of the model. In addition, we employ the Kaiser criterion, which states that only factors with eigenvalues in excess of one should be retained. ${ }^{51}$

Table 5 summarises the results of the EFA. ${ }^{52}$ As can be inferred from the rotated factor loadings matrix, we decided in favour of a five-factor model that is compatible with our hypotheses. This solution is also supported by the Kaiser criterion (see eigenvalues). ${ }^{53}$ In sum, the five factors account for more than 80 per cent of the variation in the data. Furthermore, apart from two exceptions, all factor loadings that belong to one item battery exceed 0.60 , underlining a strong influence of the common factors on the observed variables through which they have been measured. ${ }^{54}$ This is also reflected by the low number of cross-loadings above 0.4 as well as the high values for Cronbach's $\alpha$, which measures the internal consistency of each factor. Thus, the 26 items that have been included in the EFA lead to a meaningful factor structure. In line with our arguments in the section "Development of hypotheses", we interpret the five factors as follows:

- Factor 1: expertise and experience with regard to the cat bond asset class (Hypothesis 3)

- Factor 2: perceived availability of data and information on the cat bond asset class (Hypothesis 7)

- Factor 3: perceived attractiveness of the risk-return profile (Hypothesis 4)

- Factor 4: perceived administrative complexity (Hypothesis 6)

- Factor 5: perceived fit with the insurance company's ALM strategy (Hypothesis 2)

\section{Logistic regression results}

This EFA output enables us to test five of our eight hypotheses within a logistic regression analysis. In order to control for the remaining three potential determinants, we need to draw on further independent variables. More specifically, two of the 15 items that were not suited for the EFA have been averaged to form an additional factor, reflecting Hypothesis 4 (diversification benefits of cat bonds). In addition, we include the number of employees as a proxy for the firm size (Hypothesis 1$).{ }^{55}$ Finally, to account for

${ }^{51}$ Being defined as the sum of squared factor loadings across all items, eigenvalues represent the amount of the total variance explained by a factor. As EFA is commonly performed with standardised variables, each item exhibits an eigenvalue of one. Thus, intuitively the Kaiser criterion requires factors to explain at least as much variance as individual items.

${ }^{52}$ In order to enhance the readability and interpretability of this table, factor loadings below 0.4000 have been suppressed.

${ }^{53}$ Note that there is actually a sixth factor, which exhibits an eigenvalue just slightly above one. However, it contributes a mere 3.85 per cent of explained variance and is neither supported by our theory, nor clearly associated with a specific item battery. In addition, no item exhibits a loading in excess of 0.6 with regard to this factor. Hence, we chose not to include it in the final factor model.

${ }^{54}$ The factor loadings can be interpreted as correlation coefficients between indicator variables and factors.

${ }^{55}$ We have also estimated alternative model specifications based on the balance sheet size and the premium volume to ensure that the reported significance level for the size factor is robust with regard to the employed proxy. 
Table 6 Logistic regression with all potential determinants

\begin{tabular}{|c|c|c|c|c|c|c|}
\hline$N=36$ & $\beta_{k}$ & $\exp \left(\beta_{k}\right)$ & s.e. & Wald & p-value & sig. \\
\hline Constant & 0.3867 & 1.4721 & 0.9034 & 0.1832 & 0.6686 & \\
\hline Company size & -0.0002 & 0.9998 & 0.0001 & 1.6369 & 0.2008 & \\
\hline Expertise and experience & 3.5537 & 34.9413 & 1.6473 & 4.6537 & 0.0310 & $* *$ \\
\hline Perceived fit with strategic ALM & 3.0297 & 20.6905 & 1.4511 & 4.3591 & 0.0368 & $* *$ \\
\hline Perceived data availability & 0.4424 & 1.5565 & 0.6264 & 0.4989 & 0.4800 & \\
\hline Perceived administrative complexity & -0.8880 & 0.4115 & 0.8645 & 1.0550 & 0.3044 & \\
\hline Perceived risk-return profile & 0.1325 & 1.1416 & 0.6774 & 0.0382 & 0.8449 & \\
\hline Perceived diversification benefits & 0.5492 & 1.7319 & 0.6929 & 0.6283 & 0.4280 & \\
\hline Regulatory constraints & -4.9872 & 0.0068 & 2.5702 & 3.7652 & 0.0523 & $* *$ \\
\hline Goodness of fit & \multicolumn{2}{|c|}{$\chi^{2}$} & \multicolumn{2}{|c|}{ d.f. } & \multicolumn{2}{|r|}{$p$-value } \\
\hline$-2 L L_{0}($ null model $)$ & \multicolumn{2}{|c|}{45.8290} & \multicolumn{2}{|c|}{34} & \multicolumn{2}{|r|}{0.0847} \\
\hline$-2 L L_{m}$ (considered model) & \multicolumn{2}{|c|}{20.3100} & \multicolumn{2}{|c|}{26} & \multicolumn{2}{|r|}{0.7766} \\
\hline$L R$ (likelihood ratio test) & \multicolumn{2}{|c|}{25.5190} & \multicolumn{2}{|c|}{8} & \multicolumn{2}{|r|}{0.0013} \\
\hline$H L$ (Hosmer-Lemeshow test) & \multicolumn{2}{|c|}{10.2841} & \multicolumn{2}{|c|}{7} & \multicolumn{2}{|r|}{0.1730} \\
\hline
\end{tabular}

Pseudo $R^{2}$-measures

\begin{tabular}{ll}
\hline Cox and Snell & 0.5078 \\
Nagelkerke & 0.7053 \\
McFadden & 0.5568
\end{tabular}

Results for a logistic regression of the dichotomous dependent variable (investor/non-investor) on eight explanatory variables (plus constant). The coefficients $\beta_{k}$ indicate the magnitude of the effect of each independent variable on the logit, $\exp \left(\beta_{k}\right)$ represents the corresponding impact on the odds, and s.e. is the standard error of the parameter. The Wald statistic is employed to test the significance of the logit coefficients. Goodness of fit (based on the $\chi^{2}$ distribution): $-2 L L_{0}=$ minus two times the log-likelihood value for the null model (includes only a constant); $-2 L L_{m}=$ minus two times the log-likelihood value for the considered model $\left(H_{0}\right.$ : perfect model fit); $L R$ (likelihood ratio) $=$ difference between $-2 L L_{0}$ and $-2 L L_{m}\left(H_{0}\right.$ : all logit coefficients of the considered model are zero); $H L=$ Hosmer-Lemeshow statistic $\left(H_{0}\right.$ : the observed and predicted event rates do not differ in each category of the dependent variable). Pseudo $R^{2}$-measures are defined between zero and one with values in excess of 0.4 indicating a good model fit. Significance levels: $* * *=1$ per cent, $* *=5$ per cent, $*=10$ per cent.

Hypothesis 8 , we coded a dummy variable for the regulatory constraints, which equals one if the company is subject to Swiss investment rules and zero otherwise.

The results for a logistic regression model, comprising these eight independent variables, are shown in Table 6. Unreported diagnostics indicate that multicollinearity is not an issue. The coefficients $\beta_{k}$ reflect the magnitude of the effect of each independent variable on the $\operatorname{logit}, \exp \left(\beta_{k}\right)$ represents the corresponding impact on the odds, and s.e. is the standard error of the parameter. The Wald statistic is employed to test the significance of the individual logit coefficients. Examining the $p$-values, we notice that the coefficients of the regressors "expertise and experience", "perceived fit with the firm's ALM strategy" and "regulatory constraints" turn out to be statistically significant. ${ }^{56}$ Consistent with the

${ }^{56}$ Note that we also conducted analyses with the 13 spare items, which are neither used in the EFA nor reflect a specific hypothesis. Five of these items cover more detailed aspects with regard to accounting treatment and solvency capital requirements, another five represent specific transactional characteristics such as TRS features 
Table 7 Classification table for model with all potential determinants

\begin{tabular}{lccc}
\hline Observed & \multicolumn{2}{c}{ Predicted } \\
\cline { 2 - 4 } & Investor & Non-investor & Correct \\
\hline Investor & 10 & 2 & 83.33 \\
Non-investor & 1 & 23 & 95.83 \\
& & Overall & 91.67 \\
\hline
\end{tabular}

This classification table can be employed to evaluate the predictive accuracy of the logistic regression model in Table 6. It shows how many of the observed values for the dichotomous dependent variable (investor/noninvestor) are correctly predicted. The figures are based on a cutoff value of 0.5 , that is, all firms for which the probability of investing as implied by the model exceeds 0.5 are classified as investors. The model correctly predicts 83.33 per cent of the investors, 95.83 per cent of the non-investors and 91.67 per cent of all cases.

respective hypotheses, the first two factors exhibit a positive impact, while the third one reduces the logit and the investment probability. All other factors, on the contrary, appear to be irrelevant with regard to the insurers' decision to add cat bonds to their asset portfolios.

Table 6 also contains the typical goodness-of-fit measures for logistic regression models. $-2 L L_{0}$ and $-2 L L_{m}$ equal minus two times the log-likelihood value for a null model that includes only a constant and minus two times the log-likelihood value for the considered model, respectively. The higher the value of $-2 L L_{m}$, the worse the actual model fit. $-2 L L_{m}$ (also known as deviance) is $\chi^{2}$-distributed with $N-k-1$ degrees of freedom ( $k$ equals the number of explanatory variables) and serves to test the null hypothesis of a perfect model fit that, due to the $p$-value of 0.7766 , cannot be rejected. ${ }^{57}$ A closely related statistic is the likelihood ratio, $L R$, which equals the difference between $-2 L L_{0}$ and $-2 L L_{m}$, thus providing a means for the assessment of the fit of the considered model relative to the null model. It is also $\chi^{2}$-distributed with degrees of freedom equal to the difference in the degrees of freedom of $-2 L L_{0}$ and $-2 L L_{m}$ and forms the basis for the likelihood ratio test. In our case, the respective null hypothesis that all logit coefficients are jointly zero can be rejected on the 1 per cent significance level ( $p$-value: 0.0013 ). Therefore, adding the tested regressors leads to a significant improvement in the model fit compared with the null model. Furthermore, we conduct the Hosmer-Lemeshow test. Based on the corresponding variable $H L$, which is $\chi^{2}$-distributed with seven degrees of freedom, it is not possible to reject the null hypothesis that the observed and predicted event rates are equal for each category of the dependent variable.

and collateral arrangements, and one asks for the respondents' overall risk perception. Unreported logistic regression results indicate that none of these variables adds any explanatory power to the model. Furthermore, additional qualitative characteristics such as the company type (primary insurer vs. reinsurer) or business line (life vs. nonlife) have been tested via dummy variables. In this regard, we find that a "reinsurance company" exhibits a significant positive impact on the investment decision. However, this can be simply explained by the fact that the corresponding dichotomous variable is highly predictable through a combination of the factors expertise/ experience as well as perceived fit with the ALM strategy, and is thus already covered by our model.

${ }^{57}$ We are aware that the $-2 L L_{m}$ statistic is sensitive to the distribution of the cases among the categories of the dependent variable. If the sample is very unbalanced in this regard, it may provide a too optimistic assessment of the model fit. 
Table 8 Logistic regression with significant determinants

\begin{tabular}{|c|c|c|c|c|c|c|}
\hline$N=36$ & $\beta_{k}$ & $\exp \left(\beta_{k}\right)$ & s.e. & Wald & p-value & sig. \\
\hline Expertise and experience & 2.4740 & 11.8694 & 0.9830 & 6.3336 & 0.0118 & $* *$ \\
\hline Perceived fit with ALM strategy & 2.2814 & 9.7899 & 0.9887 & 5.3239 & 0.0210 & $* *$ \\
\hline Regulatory constraints & -3.3251 & 0.0360 & 1.4184 & 5.4955 & 0.0191 & $* *$ \\
\hline Goodness of fit & & $\chi^{2}$ & & d.f. & & $p$-value \\
\hline$-2 L L_{0}$ (null model) & & 49.9070 & & 35 & & 0.0490 \\
\hline$-2 L L_{m}$ (considered model) & & 24.9120 & & 32 & & 0.8096 \\
\hline$L R$ (likelihood ratio test) & & 24.9950 & & 2 & & 0.0000 \\
\hline$H L$ (Hosmer-Lemeshow test) & & 4.2433 & & 7 & & 0.7514 \\
\hline
\end{tabular}

Pseudo $R^{2}$-measures

\begin{tabular}{ll}
\hline Cox and Snell & 0.5006 \\
Nagelkerke & 0.6674 \\
McFadden & 0.5008
\end{tabular}

Results for a logistic regression of the dichotomous dependent variable (investor/non-investor) on three explanatory variables (without a constant). The coefficients $\beta_{k}$ indicate the magnitude of the effect of each independent variable on the logit, $\exp \left(\beta_{k}\right)$ represents the corresponding impact on the odds, and s.e. is the standard error of the parameter. The Wald statistic is employed to test the significance of the logit coefficients. Goodness of fit (based on the $\chi^{2}$ distribution): $-2 L L_{0}=$ minus two times the log-likelihood value for the null model (includes only a constant); $-2 L L_{m}=$ minus two times the log-likelihood value for the considered model $\left(H_{0}\right.$ : perfect model fit); $L R$ (likelihood ratio) $=$ difference between $-2 L L_{0}$ and $-2 L L_{m}\left(H_{0}\right.$ : all logit coefficients of the considered model are zero); $H L=$ Hosmer-Lemeshow statistic ( $H_{0}$ : the observed and predicted event rates do not differ in each category of the dependent variable). Pseudo $R^{2}$-measures are defined between zero and one with values in excess of 0.4 indicating a good model fit. Significance levels: $* * *=1$ per cent, $* *=5$ per cent, $*=10$ per cent.

The overall good model fit indicated by these statistics is further underlined by the fact that the values of the pseudo $R^{2}$-measures by Cox and Snell, Nagelkerke, and McFadden are all above $0.4{ }^{58}$ Finally, turning to the classification table (Table 7), we find that the model correctly predicts 83.33 per cent of the investors, 95.83 per cent of the noninvestors, and 91.67 per cent of all firms. ${ }^{59}$

Since all but three of the tested independent variables turned out to be insignificant, we should be able to remove them without losing much explanatory power. The results for such a reduced model, merely comprising the regressors "expertise and experience", "perceived fit with the firm's ALM strategy" and "regulatory constraints", can be found in Table 8. Again, the coefficients for these factors are statistically significant. Moreover, as expected, the goodness-of-fit statistics and pseudo $R^{2}$-measures have hardly changed. Similarly, the figures reported in the classification table for this new

${ }^{58}$ Although they cannot be interpreted exactly in the same way, pseudo $R^{2}$-measures have been developed to mimic the well-known $R^{2}$ of the linear regression analysis (see, e.g. Wooldridge, 2008). They equal zero if the independent variables exhibit no explanatory power at all. Values above 0.4 indicate a good model fit.

59 These figures are based on a cutoff value of 0.5 , that is, all firms for which the probability of investing as implied by the model exceeds 0.5 are classified as investors. 
Table 9 Classification table for model with significant determinants

\begin{tabular}{lccc}
\hline Observed & \multicolumn{2}{c}{ Predicted } \\
\cline { 2 - 4 } & Investor & Non-investor & Correct \\
\hline Investor & 20 & 4 & 83.33 \\
Non-investor & 2 & 10 & 83.33 \\
& & Overall & 83.33 \\
\hline
\end{tabular}

This classification table can be employed to evaluate the predictive accuracy of the logistic regression model in Table 8. It shows how many of the observed values for the dichotomous dependent variable (investor/noninvestor) are correctly predicted. The figures are based on a cutoff value of 0.5 , that is, all firms for which the probability of investing as implied by the model exceeds 0.5 are classified as investors. The model correctly predicts 83.33 per cent of the investors, 83.33 per cent of the non-investors and 83.33 per cent of all cases.

model (Table 9) suggest a strong predictive accuracy. More specifically, although it includes five independent variables less than the previous model, it still correctly predicts 83.33 per cent of the investors, 83.33 per cent of the non-investors and 83.33 per cent of all firms in the sample.

To sum up, through our quantitative results, we are able to provide evidence for Hypotheses 2, 3 and 8. The remaining hypotheses, however, cannot be confirmed. Consequently, the expertise and experience of insurance companies concerning cat bonds, the extent to which they perceive a fit of the asset class with their ALM strategy and the prevailing regulatory regime seem to be the key determinants of the investment decision. To assess the importance of these factors relative to each other, one needs to consider the respective effect strengths. According to the logit coefficient of 2.4740 , the strongest impulse for an investment in cat bonds emanates from the expertise/experience of a company. With a corresponding value of 2.2814, however, the perception that the asset class is in line with the ALM strategy has a similarly large positive impact on the logit and, in turn, the probability to invest. In contrast to that, the binding regulatory constraints with regard to the tied assets faced by Swiss companies strongly oppose these factors (logit coefficient: -3.3251). Thus, Swiss insurers seem to be a lot less likely to invest in cat bonds than EU-based firms, even if they exhibit the same values with regard to the two aforementioned factors.

\section{Further qualitative results}

\section{Open survey questions}

To complement our inference statistics, we additionally included five open questions in the questionnaire. Thereby, the participants were given the opportunity to express opinions and ideas with regard to different aspects of their cat bond investment decision. Overall, we obtained 38 responses to open questions from 24 different key informants. A comprehensive list of quotations has been included in the Appendix.

For reasons of efficient reporting, we have grouped the answers in this section based on their key messages. The respective results are shown in Table 10. A total of 14 statements contain aspects that encourage the firms to invest in cat bonds. Six of 
Table 10 Open questions

Full sample

No. Per cent

Aspects encouraging cat bond investments

"Cat bonds offer attractive returns/have a low fundamental correlation with other asset classes". $6 \quad 15.79$

"It can be better to write cat bond business than to use the conventional market". $\quad 6 \quad 15.79$

"We are obtaining knowledge of the cat bond market to use these instruments in the future". 2026

Aspects opposing cat bond investments

"They do not fit with our asset and liability management".

"We have not undertaken a particular effort due to regulatory constraints".

"Missing know-how".

w-how".

Other reasons

Further comments

Total

$38 \quad 100.00$

This table gives an overview of the responses to the open questions in the survey. Twenty-four participants have commented on different aspects regarding their decision to invest or not to invest in cat bonds. The answers are categorised by aspects encouraging and aspects opposing cat bond investments. The percentage figures are based on a total of 38 responses to open questions.

these, that is, 15.79 per cent of all comments, are centred around the attractive riskreturn profile of cat bonds as well as the low correlation with other asset classes. Since these factors were not found to be statistically significant in the logistic regression analysis of the previous section, we need to assume that they are merely a decisive factor for certain insurers but not for the majority of firms. In another six responses (15.79 per cent), the respective participants point out that their companies view cat bond investments as a means for market expansion and to complement their traditional insurance business. This is quite an interesting consideration, which has not been hypothesised ex-ante and was thus missing in our questionnaire design. Hence, for the time being, we need to take into account that this might be an additional determinant while leaving the confirmation of its statistical significance for future research. Finally, two answers (5.26 per cent) name the intension to acquire know-how about the cat bond market as the main reason for the investment decision. This provides further support for $\mathrm{H}_{3}$.

Moreover, 21 answers brought forward reasons not to purchase cat bonds. Since the majority of survey participants are non-investors (see Table 1), it could be expected that the negative statements outnumber the arguments in favour of an investment in this asset class. Consistent with our statistical results for $\mathrm{H}_{2}$, a lacking fit of cat bonds with regard to the ALM considerations of the company is stressed in nine comments (23.68 per cent). Furthermore, in six responses (15.79 per cent) the key informants note that their firm refrains from cat bond investments due to regulatory constraints. Particularly the FINMA guidelines regarding "tied assets" are referred to several times, thus confirming our logistic regression results for $H_{8}{ }^{60}$ Apart from these aspects, four answers (10.53 per cent) revolve around the missing expertise and 
experience that would be needed to make adequate investment decisions with regard to cat bonds. Again, this supports our previous findings with regard to $\mathrm{H}_{3}$. Finally, the responses to the open survey questions also comprise a totally new aspect counted under "other reasons". 61 One company does not seem to show any interest in cat bond investments because they want to avoid losses due to perils that their stakeholders do not expect to be part of their exposure. The fact that earthquakes in Japan would not be associated with a purely European insurance company is mentioned as an example in this context.

Most answers to the open survey questions help to underline and further illustrate the results of our empirical analysis. Indeed, a large number of the participants made comments that can be associated with one of the three significant determinants identified in the previous section. In addition to that, we were able to gather new information with regard to the investment decision that had not been captured by the preset items in the questionnaire. The aspects revealed in this regard should be taken into account in future empirical research on this topic.

\section{Interviews with managers of dedicated cat bond funds}

Aside from the survey, we conducted structured interviews with the managers of four large and influential dedicated cat bond funds. Together, their assets under management amount to approximately US\$7.73 billion, which represented 76.19 per cent of the outstanding cat bond volume in $2011 .{ }^{21}$ Thus, our interview partners possess information about a large part of the market and profound knowledge of their clients' investment decisions as well as the reasons behind them. This characterises them as key informants for our study. The interviews were carried out in March and April 2012. All participants received the same set of questions and were asked to answer either in form of a telephone interview or in writing. The generally low level of cat bond investments in the insurance industry is also reflected by the investor base of the considered funds. While two of them do not have insurers among their current investors at all, the other two pointed out that less than 1 per cent of their total client money comes from the insurance industry. Several reasons for this phenomenon have been provided by our interview partners.

One of them emphasised that the regulatory constraints in Switzerland are the main factor behind the limited interest in cat bond investments shown by the local insurance industry. According to his clients, FINMA insists on a strict separation of business lines. Companies that are exclusively regulated as life or health insurers are not permitted to invest in cat bonds at all, since this would be economically equivalent to the underwriting of insurance contracts in the property and liability sector. Nonlife insurers, in contrast, for which natural disaster risk is part of their core business, do not face such an explicit restriction with regard to the asset class. However, their ability to conduct cat bond investments is still considerably

${ }^{60}$ A penalisation in terms of the Solvency II capital charges for cat risk, in contrast, is only criticised in a single response.

${ }^{61}$ The second statement in the category "other reasons" refers to the low degree of liquidity of cat bonds. This consideration is covered by factor 4 of the empirical analysis (perceived administrative complexity). 
constrained due to the tied asset investment rules set by FINMA. This statement provides further support for $H_{8}$.

Other explanations revolved around the determinant expertise and experience. Our interviewees find this aspect to be especially relevant in times of market turbulence. Under such circumstances, as during the financial crisis in 2008, those insurance firms without in-depth knowledge about the cat bond market are the first to abandon their engagement as investors. It has also been stated that there are a number of reinsurers as well as large primary insurers with considerable cat bond expertise and experience. These firms only consider direct investments. Smaller insurers, on the other hand, often lack know-how with regard to the structures, the market, or certain catastrophe risks in general and thus, if at all, access the asset class through dedicated cat bond funds. We view these arguments as an additional confirmation of $\mathrm{H}_{3}$.

Furthermore, the question whether the risk-return and correlation profiles of cat bonds have a certain impact on the investment decision was affirmed during three of the interviews. This is in line with the statements of some of the survey participants. Hence, those insurers that actually invest in cat bonds might view the beneficial characteristics of the asset class to be great enough to overcome some of the other factors that exhibit a negative impact on their investment decision. Nevertheless, the corresponding determinants did not turn out to be statistically significant in our empirical analysis, implying that one should be cautious about a generalisation of these opinions. Ultimately, in the absence of further evidence, $H_{4}$ and $H_{5}$ cannot be confirmed.

Moreover, three interview partners stated that an improvement in the availability of data and information on the cat bond asset class could have a positive influence on the demand. In this context, they pointed to a potentially severe conflict of interest. Since the asset management of those insurance companies that act as cat bond investors needs to assess prospective transactions, it desires as much publicly available information as possible. The sponsor, in contrast, is interested in a high level of discretion, particularly for indemnity deals, in order to avoid that its competitors gain too much insight into its underwriting activities. Consequently, insurers seem to believe that they can get better data on the actual exposure when they insure the risk rather than relying on offering documents of cat bond transactions. Moreover, it has been mentioned that substantial changes in the risk models of the major analytics firms (RMS, EQECAT, AIR) negatively affect the interest in the asset class, since investors generally tend to avoid cat bonds that are perceived to hide a considerable amount of model risk. Although these are interesting new insights, the insignificance of the respective factor within the empirical analysis prevents the confirmation of $\mathrm{H}_{7}$.

Finally, the interviews revealed two perspectives concerning the cat bond investment decision of insurance companies that we had not anticipated by our hypotheses. Interestingly, these are consistent with the new aspects that we identified based on the answers to the open survey questions. The first point, which has been mentioned by two of the interviewees, can be described as political reasons for the decision not to buy cat bonds. More specifically, although stakeholders might benefit from this asset class through enhanced diversification, the management of insurance companies can be reluctant to accept exposures outside of their core market due to the 
associated career risks. In doing so, they aim to avoid the responsibility for natural hazard losses in locations where their company is not represented with its insurance operations. Apart from that, our interview partners indicated that a few firms have embraced cat bonds as a complement to their conventional business. While some insurers exclusively approach the topic from an asset management perspective, others consider ILS investments as a relative value trade with regard to insurance products. If the pricing of a cat bond issue is more attractive than that of a corresponding traditional contract, these companies will switch to the former in order to benefit from its superior risk-return trade-off.

\section{Summary and conclusion}

Our main research goal in this article is to identify major determinants of the cat bond investment decision of insurers. For this purpose, we have conducted a comprehensive survey among senior executives in the European insurance industry. Evaluating the corresponding data set by means of EFA and logistic regression methodology, we are able to show that the expertise and experience with regard to cat bond investments, their perceived fit with the prevailing ALM strategy and the regulatory regime exert a significant influence on an insurer's propensity to invest. In contrast to that, the perception of the risk-return profile, diversification benefits, administrative complexity, as well as the availability of data and information seem to be of lesser relevance. Similarly, we do not find evidence for an impact of firm size, accounting treatment or solvency capital requirements. These statistical results are complemented by further qualitative survey answers and additional information from structured interviews with the managers of four large dedicated cat bond funds.

Our findings should be highly relevant to cat bond issuers and policymakers alike. Since, in general, insurance companies represent a central source of institutional investor demand in the capital markets, the reduction of existing investment barriers with regard to cat bonds might generate a substantial growth impulse for this asset class. It appears that, theoretically, issues relating to the first two determinants (lack of expertise/experience, perceived fit with the ALM strategy) could be simply overcome by properly educating prospective market participants and disseminating more information about the merits of adding cat bond exposure to the balance sheet of a typical insurance company. Particularly life insurers should be able to exploit the virtues of the instrument, since it may serve as a diversification tool for both their asset and liability risks. Impediments arising due to regulatory constraints such as the rigid legal investment guidelines set by FINMA, however, seem a lot more difficult to address. In this respect, an intensive dialogue with the supervisory authority is required to highlight that, from a risk sharing and performance perspective, it may be economically reasonable to permit the allocation of a limited fraction of the tied assets to cat bonds.

Future work could be aimed at overcoming some of the limitations of our study. The most important aspect in this regard relates to sample size. Indeed, it would be helpful to verify our results based on a much broader survey, for example, including U.S. insurance companies or even adopting a global scope. In addition, the qualitative 
information that was gathered through open survey questions and structured interviews raised completely new aspects for which measurement variables had not been incorporated in our original questionnaire design. Hence, an examination of the statistical significance of these potential determinants is still outstanding.

\section{Acknowledgements}

We are grateful to Andreas Lindemuth and Stephan Schreckenberg of Swiss Re for supporting the idea for this paper and providing helpful comments and suggestions.

\section{References}

AnlV (2011) 'Verordnung über die Anlage des gebundenen Vermögens von Versicherungsunternehmen (Anlageverordnung)', www.bafin.de.

AVO (2009) 'Verordnung über die Beaufsichtigung von privaten Versicherungsunternehmen (Aufsichtsverordnung)', www.admin.ch.

Bantwal, V.J. and Kunreuther, H.C. (2000) 'A cat bond premium puzzle?' Journal of Behavioral Finance 1(1): 76-91.

Barrieu, P. and Loubergé, H. (2009) 'Hybrid cat bonds', Journal of Risk and Insurance 76(3): 547-578.

Bouriaux, S. and MacMinn, R. (2009) 'Securitization of catastrophe risk: New developments in insurancelinked securities and derivatives', Journal of Insurance Issues 32(1): 1-34.

Braun, A. (2012) 'Pricing in the primary market for cat bonds: New empirical evidence' Working Papers on Risk Management and Insurance, No. 116, Institute of Insurance Economics, University of St. Gallen.

Cummins, J.D. (2005) 'Convergence in wholesale financial services: Reinsurance and investment banking', The Geneva Papers on Risk and Insurance - Issues and Practice 30(2): 187-222.

Cummins, J.D. (2008) 'CAT bonds and other risk-linked securities: State of the market and recent developments', Risk Management and Insurance Review 11(1): 23-47.

Cummins, J.D. and Trainar, P. (2009) 'Securitization, insurance, and reinsurance', Journal of Risk and Insurance 76(3): 463-492.

Cummins, J.D. and Weiss, M.A. (2009) 'Convergence of insurance and financial markets: Hybrid and securitized risk-transfer solutions', Journal of Risk and Insurance 76(3): 493-545.

Directive 92/49/EEC (1992) 'Council directive 92/49/EEC of 18 June 1992 on the coordination of laws, regulations and administrative provisions relating to direct insurance other than life assurance and amending directives 73/239/EEC and 88/357/EEC (third non-life insurance directive)', www.eur-lex .europa.eu.

Directive 2002/83/EC (2002) 'Directive 2002/83/EC of the European parliament and of the council of 5 November 2002 concerning life assurance', www.eur-lex.europa.eu.

Froot, K.A. (1999) 'The evolving market for catastrophic event risk', Risk Management and Insurance Review 2(3): 1-28.

Froot, K.A. (2001) 'The market for catastrophe risk: A clinical examination', Journal of Financial Economics 60(2-3): 529-571.

Gibson, R., Habib, M.A. and Ziegler, A. (2007) Why have exchange-traded catastrophe instruments failed to displace reinsurance?, EFA 2007 Ljubljana Meetings Paper.

Guy Carpenter (2011) World Catastrophe Reinsurance Market Review, September.

Hagendorff, B., Hagendorff, J. and Keasey, K. (2011) The risk implications of insurance securitization: Do catastrophe bonds lower the default risk of issuers? Working Paper, Leeds University.

Ibragimov, R., Jaffee, D. and Walden, J. (2009) 'Non-diversification traps in catastrophe insurance markets', Review of Financial Studies 22(3): 959-993.

Jöreskog, K.G. (1967) 'Some contributions to maximum likelihood factor analysis', Psychometrika 32(4): 443-482.

Kaiser, H. (1974) 'An index of factorial simplicity', Psychometrika 39(1): 31-36. 
KAVO (2012) 'Verordnung der Finanzmarktaufsichtsbehörde (FMA) über Kapitalanlagen zur Bedeckung der versicherungstechnischen Rückstellungen durch Unternehmen der Vertragsversicherung (Kapitalanlageverordnung)', www.fma.gv.at.

Lakdawalla, D. and Zanjani, G. (2011) 'Catastrophe bonds, reinsurance, and the optimal collateralization of risk transfer', Journal of Risk and Insurance 79(2): 449-476.

Likert, R. (1932) 'A technique for the measurement of attitudes', Archives of Psychology 22(140): 1-55.

Litzenberger, R.H., Beaglehole, D.R. and Reynolds, C.E. (1996) 'Assessing catastrophe reinsurance-linked securities as a new asset class', Journal of Portfolio Management 23(Special Issue): 76-86.

Merton, R.C. (1974) 'On the pricing of corporate debt: The risk structure of interest rates', Journal of Finance 29(2): 449-470.

Niehaus, G. (2002) 'The allocation of catastrophe risk', Journal of Banking and Finance 26(2-3): 585-596.

Sawilowsky, S.S. and Blair, R.C. (1992) 'A more realistic look at the robustness and type II error properties of the $t$ test to departures from population normality', Psychological Bulletin 111(2): 352-360.

Schoechlin, A. (2002) 'Where's the cat going? Some observations on catastrophe bonds', Journal of Applied Corporate Finance 14(4): 100-107.

Swiss Financial Market Supervisory Authority (FINMA) (2008) 'Anlagen im gebundenen Verm̈ogen sowie Einsatz von derivativen Finanzprodukten bei Versicherern', Rundschreiben 2008/18.

Swiss Re (2006) Securitization: New opportunities for insurers and investors, Sigma No.7, Zurich, Switzerland.

Swiss $\operatorname{Re}(2009)$ The role of indices in transferring insurance risk to the capital markets, Sigma No.4, Zurich, Switzerland.

Towers Watson (2010) Catastrophe bonds evolve to address credit risk issues/, Report (May).

VAG Austria (2012) 'Bundesgesetz vom 18. Oktober 1978 über den Betrieb und die Beaufsichtigung der Vertragsversicherung (Versicherungsaufsichtsgesetz)', www.fma.gv.at.

VAG Germany (2012) 'Gesetz über die Beaufsichtigung der Versicherungsunternehmen (Versicherungsaufsichtsgesetz)', www.bafin.de.

VAG Switzerland (2011) 'Bundesgesetz betreffend die Aufsicht über Versicherungsunternehmen (Versicherungsaufsichtsgesetz)', www.admin.ch.

Wooldridge, J.M. (2008) Introductory Econometrics: A Modern Approach, $4^{\text {th }}$ edn. Mason, OH: South-Western CENGAGE Learning.

World Economic Forum (2008) Convergence of insurance and capital markets, Report (October).

\section{Appendix}

\section{Answers to the open survey questions}

\section{Aspects encouraging cat bond investments}

Risk-return profile and diversification benefits

- Attractive returns. (Germany; Reinsurer; Director)

- Decent expected return proposition. (Finland; Primary Insurer; Portfolio Manager)

- Attractive returns. (Switzerland; Reinsurer; Head of Nonlife Risk Transformation)

- Potentially attractive spreads. (Switzerland; Primary Insurer)

- Cat bond returns typically have a low fundamental correlation with other asset classes.

(Finland; Primary Insurer; Portfolio Manager) 
- Diversification.

(Switzerland; Primary Insurer)

- Sigma No. 7/2006, Zurich, Switzer Land: Swiss Re.

Market expansion/complement the traditional insurance business

- For visibility in this market place - it can be better to "write" cat bond business than to use the conventional market.

(U.K.; Reinsurer; Managing Director)

- Market expansion. (Italy; Primary Insurer; Managing Director)

- Certain risks are not available in form of traditional reinsurance. (Germany; Reinsurer; Director)

- Due to the evolution of the business it could be interesting to invest in this asset class. (Italy; Primary Insurer; Director)

- Market making. (Switzerland; Reinsurer; Head of Nonlife Risk Transformation)

- Cat bonds are the most liquid asset class inside the nonlife risk category. (Finland; Primary Insurer; Portfolio Manager)

Expertise and experience with regard to the instrument

- To test the market. (Sweden; Reinsurer; Group CFO)

- Obtaining knowledge of the cat bond market to use these instruments in the future. (Netherlands; Primary Insurer; Senior Risk Manager)

Aspects opposing cat bond investments

Fit with strategic asset and liability management goals

- At the moment, they do not exactly fit in our asset and liability management. (Italy; Primary Insurer)

- The decision not to invest in cat bonds is based on a total balance sheet view and the regional risk profile of our company.

(Switzerland; Primary Insurer; Director)

- We are very conservative in our investment approach. (Greece; Primary Insurer)

- Do not fit our ALM considerations. (Austria; Primary Insurer; Market Risk Manager)

- Main focus in matching liabilities. (Finland; Primary Insurer; Chairman of the Board)

- Strategic decision. Ultimately, we do not want to buy risks that we already insure. (Switzerland; Primary Insurer; CIO)

- We do not treat them as investments, since they are correlated with our key cat risks. (U.K.; Reinsurer; Managing Director)

- We acquire our cat risk through insurance and feel no need to buy it through assets. (Portugal; Primary Insurer; CFO) 
- As a reinsurer we are already exposed to natural disasters risk. Investing in cat bonds would create a dependency between our insurance results and investment results.

(Belgium; Reinsurer; Member of the Executive Board)

Regulatory constraints

- We have not undertaken a particular effort due to regulatory constraints. (Switzerland; Primary Insurer; Head of Investments)

- Not allowed to invest according to FINMA rules guiding "Gebundene Vermögen" (tied assets), therefore no particular efforts undertaken. (Switzerland; Primary Insurer; Head of Asset Management)

- All our investments need to qualify for tied assets. Considering the local asset management knowledge/team, these investments will not qualify as "tied assets" and hence we cannot invest.

(Switzerland; Primary Insurer; Risk Manager)

- See FINMA regulation covering "Gebundene Vermögen" (tied assets)

(Switzerland; Primary Insurer; Head of Investments)

- We maintain a very low risk profile, which ensures that we meet the Swiss regulatory tied assets requirement.

(Switzerland; Primary Insurer; Controller)

- Under Solvency II, cat risk is heavily penalized in terms of capital requirements. (Portugal; Primary Insurer; CFO)

Expertise and experience with regard to the instrument

- Missing know-how. (Italy; Primary Insurer; Director)

- We are more confident in traditional investment asset classes. (Italy; Primary Insurer; Director)

- Opacity: We have difficulties to properly value cat bonds. (Switzerland; Primary Insurer)

- The risk exposures and the risk accumulation are difficult to assess and monitor. (Switzerland; Primary Insurer; CIO)

Other reasons

- Although the risk-return profile is very interesting, it can be difficult to explain to our stakeholders that we could have made a loss due to a peril that our stakeholders don't expect to be our risk. For example, a Japanese earthquake is not a peril that our stakeholders expect to cause a loss for an insurer only active in Europe.

(Netherlands; Primary Insurer; Senior Risk Manager)

- Not very liquid

(Italy; Primary Insurer; Managing Director)

Further comments

- We have only invested in a cat bond fund that has no specific restrictions. (Italy; Primary Insurer) 
- Our ILS investments are not covered by our ordinary asset management activities but are managed by our dedicated ILS department, which is part of the reinsurance division. (Germany; Reinsurer; Director)

- The entity in our group that holds cat bonds is a Bermudian affiliate.

(U.K.; Reinsurer; Managing Director)

\section{About the Authors}

Alexander Braun holds a Ph.D. in Finance from the University of St. Gallen (Switzerland) and a Diplom-Kaufmann degree from the University of Mannheim (Germany). He currently works as project leader and postdoctoral researcher at the Institute of Insurance Economics of the University of St. Gallen. Before joining the Institute of Insurance Economics, he was Senior Analyst (fixed income) in the European Capital Markets Division of Lehman Brothers in London. His main research areas are insurance-linked securities, financial services regulation, risk management, and insurance economics.

Katja Müller obtained the degree Diplom-Wirtschaftsmathematikerin from the University of Ulm, Germany, in 2011. During her studies she spent two semesters abroad at the Florida Institute of Technology, USA, where she received a Master of Science in Applied Mathematics. In January 2011, she joined the Institute of Insurance Economics at the University of St. Gallen, Switzerland, as a research assistant and Ph.D. candidate. Her main research revolves around the topics risk management and insurance fraud.

Hato Schmeiser studied business administration at the University of Mannheim. After his doctoral degree and postdoctoral lecture qualification (Habilitation) in 2003 (Humboldt Universität zu Berlin), he was appointed Professor for Insurance and Risk Management at the University of Münster. Since 2005, he holds the Chair for Risk Management and Insurance and is Managing Director of the Institute of Insurance Economics at the University of St. Gallen. His main research interests include individual financial planning, dynamic financial analysis, option pricing, and regulation of financial firms. 